\section{A Community Based study on Breast Feeding Practices in Gampaha District}

\author{
${ }^{1}$ A Jayatilleka $\quad{ }^{2}$ DN Frnando
}

\begin{abstract}
Objective: To determine the prevalence of exclusive breast feeding, the predominant breast feeding rate and the bottle feeding rate, and to identify the factors influencing exclusive breast feeding in the Gampaha district.
\end{abstract}

Methodology: A sample of 1075 mothers, each with a child aged less than 365 days was identified from two randomly selected Medical Officer of Health areas. Information related to birth and feeding practices were obtained using an interviewer-administered structured questionnaire. Mothers' knowledge on breastfeeding was also assessed.

Results: Initiation of breast feeding was universal, with an exclusive breast feeding rate (EBF) of $63.7 \%$. Logistic regression analysis identified that 'mother working outside the home', delivery being not a normal delivery, not receiving antenatal education and poor knowledge on EBF were negatively associated with $\mathrm{EBF}$.

Conclusions: Even though an improvement in the EBF rate is seen over the past years, there is a need to strengthen antenatal and post-natal practices to encourage EBF and to develop innovative strategies to promote EBF among working women.

\section{Introduction}

Breast milk provides the best possible nutrition for the child's physical and mental development. Studies have continued to demonstrate the reduction of mortality and morbidity associated with breast-feeding $(1,2)$. Even though the importance of breast-feeding has been well documented, exclusive breast-feeding is a

\footnotetext{
${ }^{1}$ Medical Officer, Family Health Bureau, Ministry of Health.

${ }^{2}$ Professor and Head, Department of Community Medicine, Faculty of Medicine, University of Colombo.
}

relatively new entity. Studies have shown that all beneficial effects of breast-feeding are enhanced by ensuring the practice of exclusive breastfeeding (EBF) during the first $4-6$ months of life (3).

Reports from Sri Lanka in the 1980s and 1990s indicate that even though initiation of breastfeeding has been almost universal, introduction of formula milks early in infancy has been a frequent occurrence $(4,5)$. In view of the emphasis placed on EBF as a factor promoting child health, this study was carried out to determine the prevalence of exclusive breastfeeding, predominant breast-feeding rate and bottle-feeding rate, and to identify factors influencing EBF.

\section{Methodology}

A community based cross-sectional descriptive study design was used to study the breast feeding practices in the Gampaha district, one of the three districts in the Western Province of Sri Lanka, with a population of approximately $1,400,000$.

Two out of the 14 health areas in the district were randomly selected. All mothers resident in the selected areas who had a child less than 365 days of age on the day of the study, were identified using the Birth and Immunization Register maintained by the Public Health Midwife as the sampling frame. A total of 1075 mothers were thus identified. Mothers of infants who had congenital abnormalities or were ill at the time of the study, were excluded.

An interviewer administered structured questionnaire was used to collect information related to the birth of the child, feeding during the first few hours after birth, hospital practices related to infant feeding, reasons for starting other fluids, antenatal and postnatal support for exclusive breast-feeding and the current feeding history. The questionnaire included a 24-hour recall of food/fluids given to the infant. All interviews were conducted during a home visit and the respondent was the mother. A questionnaire was used to assess the level of knowledge of the mother on breast-feeding. The score developed, was used to assess the level of knowledge.

Ten pre -intern medical officers were trained as interviewers. Data collection of all study units 
from one health area was carried out within a period of approximately 2 weeks.

A multivariate analysis using a logistic regression model was applied to identify the factors associated with exclusive breast-feeding.

\section{Results}

Of the 1075 infants, $51.7 \%$ were males and $48.3 \%$ females. $95.1 \%$ were singleton deliveries while $4.9 \%$ were twin deliveries. The majority, $79.6 \%$, were normal deliveries and $15 \%$ were

Table 1. Indicators related to breast feeding

\begin{tabular}{ll}
\hline Indicator & Rate \% \\
\hline Exclusive breast feeding rate & 62.9 \\
Predominant breast feeding rate & 75.8 \\
Bottle feeding rate & 44.4 \\
Ever Breast-fed Rate & 100 \\
Timely First-sucking Rate & 75.1 \\
\hline
\end{tabular}

deliveries by caesarean section.

Definitions given by WHO in $1991^{1}$ were used in assessing breast feeding practices (5). Ever breast-fed rate among these infants was $100 \%$ indicating that breast-feeding is universal in the study area. The EBF rate was $62.9 \%$ with the predominant breast-feeding rate being $75.8 \%$. Predominant breast-feeding rate was higher than the EBF rate, indicating that some mothers gave other fluids and food items during first four months.(Table 1)

Study of the EBF rate by age (in months) shows that this rate was lowest during the first month $(54.3 \%)$, increased to $71 \%$ during the second month and then declined to $63.3 \%$ and $58.7 \%$ during the third and the fourth month respectively (Table 2 ). Of the infants in the first month of life, $43 \%$ were given the ayurvedic preparation referred to as 'Ratha kalke' and/or other fluids such as coriander water, tea and water. According to the WHO (5), an infant if given any medication in addition to breast milk could be considered as being exclusively breastfed. Assuming that 'Ratha kalke' is a medication, exclusive breast-feeding rate during the first month increases to $65.2 \%$. Comparison of EBF

Table 2 . Distribution of infants by age and by practice of exclusive breast feeding and predominant breast feeding

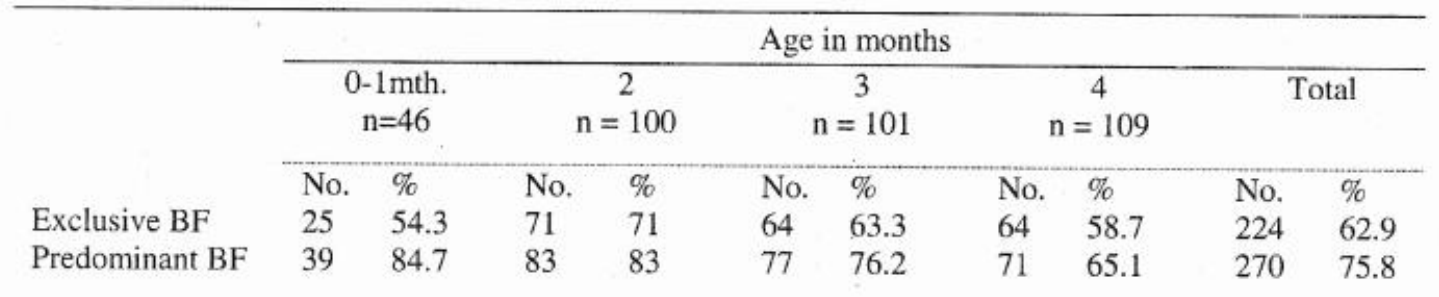

${ }^{1}$ Ever breast fed rate - Proportion of infants less than 12 months of age who were ever breast fed; Timely first suckling rate - Proportion of infants less than 12 months of age who first sucked within one hour of birth; Exclusive breast feeding rate (EBF) - Proportion of infants less than 4 months of age who are exclusively breast fed in the last 24 hours; Predominant BF rate Proportion of infants less than 4 months of age who were predominantly breast fed; Bottle feeding rate - Proportion of infants less than 12 months of age who are receiving any food or drink from a bottle. rates and the predominant breast-feeding rates for each age group indicates that the predominant breast-feeding rate was $10-30 \%$ higher than the EBF.

Timely first-sucking rate for the study sample was $75.1 \%$ indicating that a majority of babies were breast fed within the first hour of birth. Out of all infants in this study, $44.4 \%$ were bottle-fed at the time of the study. They were given a variety of food items with the bottle.

Influence of selected maternal factors (age, parity, educational level, ethnic group), infant characteristics (sex, place in the family), practices related to antenatal, natal and postnatal care and mother's knowledge on exclusive 
breast-feeding on the practice of EBF was studied. The summary of the findings are presented in Table 3 . The variables shown to have a significant negative influence on EBF were: poor knowledge on exclusive breastfeeding, delivery other than normal vaginal delivery, not receiving antenatal education on breast feeding and the mother working outside the home.
Out of 348 mothers who introduced artificial milk, $48(13.5 \%)$ did so before the infant completed 4 months of age. Among the reasons for introduction of artificial milks were: not enough milk $(60.9 \%)$, advised by medical personnel $(50.2 \%)$ and advised by field level health personnel $(33 \%)$. Elders influenced the decision in $29.3 \%$ of the mothers. The majority of mothers gave more than one answer (Table 5).

Table 3 . Variations associated with exclusive breast feeding - results of the logistic regression analysis

\begin{tabular}{|c|c|c|c|c|c|}
\hline Parameter & Comparison & Estimate & $\begin{array}{l}\text { Standard } \\
\text { error }\end{array}$ & Odds ratio & $\begin{array}{c}\text { Confidence } \\
\text { interval }\end{array}$ \\
\hline$b^{0}$ & & 0.3097 & 0.374 & & \\
\hline $\begin{array}{l}\text { Knowledge on } \\
\text { EBF }\end{array}$ & Poor vs. satisfactory & -0.4961 & 0.251 & 0.6089 & $(0.37-0.90)$ \\
\hline Type of delivery & Caesarian vs. normal & -0.5417 & 0.317 & 0.5817 & $(0.31-1.08)$ \\
\hline Type of delivery & $\begin{array}{l}\text { Forceps or vacuum } \\
\text { extraction vs. normal }\end{array}$ & -1.104 & 0.550 & 0.3316 & $(0.11-0.97)$ \\
\hline $\begin{array}{l}\text { Antenatal } \\
\text { education }\end{array}$ & Not received vs. received & 0.6170 & 0.360 & 0.5396 & $(0.27-1.09)$ \\
\hline $\begin{array}{l}\text { Mother's } \\
\text { employment }\end{array}$ & $\begin{array}{l}\text { Not employed vs. } \\
\text { employed }\end{array}$ & 0.6139 & 0.381 & 1.848 & $(0.87-3.9)$ \\
\hline
\end{tabular}

Of the entire group, 40 (3.7\%) mothers had completely stopped breast-feeding at the time of the study, among whom $0.74 \%$ of mothers had done so before the infant completed 6 months of age. The majority $(75 \%)$ of the mothers did so as they believed that they did not have enough milk. Other common reasons given were: poor suckling by baby $(42.5 \%)$, refusal by the infant $(35 \%)$, and having to go back to work $(12.5 \%)$. Many mothers gave more than one reason (Table 4). The working mothers did not commonly practice giving expressed breast milk. Only $20 \%$ of the working mothers had routinely given expressed breast milk.

Table 4. Reasons for stopping breast-feeding

\begin{tabular}{lll}
\hline $\begin{array}{l}\text { Reasons for stopping } \\
\text { breast feeding* }\end{array}$ & $\begin{array}{l}\text { Number } \\
(\mathrm{n}=40)\end{array}$ & Percentage \\
\hline Not enough milk & 30 & 75.0 \\
Poor suckling by baby & 17 & 42.5 \\
Child refused & 14 & 3.5 \\
Working mother & 05 & 12.5 \\
Child ill & 03 & 7.5 \\
Mother ill & 02 & 5.0 \\
\hline
\end{tabular}

* Some mothers gave more than one reason

\section{Discussion}

The ever breast fed rate of $100 \%$ observed in this study compares well with findings of the other studies $(4,5,7)$ while the EBF rate of $62.9 \%$ was higher compared to data from the Demographic and Health Surveys of 1993 and 2000 which reported the prevalence of EBF among children aged 4 months or less, to be $24 \%$ and $50.8 \%$ respectively.

Table 5. Reasons for introduction of artificial milk

\begin{tabular}{lll}
\hline $\begin{array}{c}\text { Reasons for stopping breast } \\
\text { feeding** }\end{array}$ & $\begin{array}{c}\text { Number } \\
(\mathrm{n}=348)\end{array}$ & Percentage \\
\hline Not enough milk & 212 & 60.9 \\
Advice by elders & 102 & 29.3 \\
Advice by field health staff & 115 & 33.0 \\
$\begin{array}{l}\text { Advice by other health staff } \\
\text { Because the elder child was } \\
\text { given such milks }\end{array}$ & 175 & 50.2 \\
Working mother & 80 & 22.9 \\
\hline ** Some mothers gave more than one reason
\end{tabular}

Being a cross sectional study, each age group included a different birth cohort of children. The study of variations in the EBF rates by the age of the child was clearly seen with a relatively lower 
EBF rates in the group with of 0-1 month old children $(65.2 \%)$ with $71 \%$ in the second month and $63 \%$ during the $3 \mathrm{rd}$ month. Study findings indicated that $32-35 \%$ of the infants have been given either water or glucose water during the first month of life and the percentage given other fluids declined to about $5-15 \%$ during the second month. The findings of DHS, 2000 (7) which included a sample from seven provinces of Sri Lanka, shows a higher EBF rate of $83.9 \%$ during the first month of life and a decline as the child grows older (The EBF rate of $65 \%$ among infants $2-3$ months), the pattern being different from that observed in the present situdy.

Even though the available information does not permit a clear explanation for the differences between the findings of the present study carried out in 1999 and DHS, 2000, these differences could be due to variations in the sample characteristics and/or due to true variations in the EBF rate among the two groups, specially during the first month.

It is possible that in selected population groups, other factors could influence such changes in EBF practice. For example, Sorenson et al (8) in their study in the plantation sector in Sri Lanka reported an EBF rate of $73 \%$ during the first month, which showed a marked decline to $23 \%$ during the second month. The likely explanation for this difference is that the women in the plantations are a predominantly working population and the change in the EBF practices was related to the mother having to 'return to work'. A study carried out in 12 out of the 24 districts in Sri Lanka in the early '80s, identified employment of women outside the home as a factor that influenced early introduction of artificial milk (4). It is worth noting that even after nearly two decades of highlighting the influence of work on breast-feeding and after adopting changes to the Maternity Benefits Ordinance (9), employment of the mother still continues to be an important factor which has a negative influence on breast feeding practices in Sri Lanka. This indicates the need for innovative approaches to be developed to enable workingwomen to continue breast-feeding such as promoting the use of expressed breast milk.

The practice of exclusive breast-feeding was positively associated with having received educational inputs on breast-feeding during the antenatal period and a satisfactory level of knowledge of the mother on exclusive breast- feeding. Similar findings have been reported in other studies $(10,11)$. It is reported that in Sri Lanka, almost $98 \%$ of pregnant women receive antenatal care (6). Thus, paying more attention to improving educational activities on exclusive breast-feeding aimed at pregnant women during the antenatal period is an important strategy that could be considered to be feasible and effective in promoting exclusive breast-feeding practices.

Mothers who have had a normal delivery, practiced exclusive breast feeding more than mothers who delivered other wise e.g. caesarian section, a forceps delivery or a vacuum extraction. Perez-Escamilla (12) identified delivery by caesarian section as a risk factor for not initiating breast-feeding, and for breast feeding for less than one month. Paying emphasis on proper management of mothers with complicated deliveries could promote EBF.

The reasons given for discontinuation of exclusive breast-feeding such as 'not enough milk' $(75 \%)$, child refusal $(35 \%)$ and poor suckling by baby $(42.5 \%)$ are very similar to those documented in other studies from Sri Lanka $(4,7)$.

The bottle-feeding rate was $44.4 \%$ in the study area. Only $3.7 \%$ of the mothers stopped breastfeeding before the age of 1 year, while $32.9 \%$ of the infants received artificial milk "indicating that most mothers practised mixed feeding. The commonest reason for introduction of artificial milk was the assumption that they do not have enough milk. .

The findings of the study highlight the need for strengthening the existing maternal health services by providing additional training of the relevant personnel, which will enable them to promote EBF, through improved communication strategies.

\section{Acknowledgements}

We wish to thank the Provincial Director of Health Services, Western Province, Deputy Provincial Director, Colombo, Medical Officers of Health and their staff in the study areas and all mothers who participated in the study. Financial assistance provided by UNICEF is gratefully acknowledged. 


\section{References}

1. Feacham RG, Koblinsk MA Interventions for the control of diarrhoea among young children: promotion of breast feeding. Bulletin of the World Health Organization 1984; 62: 271-91.

2. Victoria CG, Vaughn JP, Lombardi $\mathrm{C}$ et al Evidence for protection by breast feeding against deaths from infectious diseases in Brazil. The Lancet 1987; $2: 319-22$.

3. Popkin BM, Adair L, Akin JS. et al Breast feeding and diarrhoeal morbidity Paediatrics 1990; 86: 874-82.

4. Soysa PE, Fernando DN Factors influencing infant feeding patterns in Sri Lanka Ceylon Journal of Medical Sciences 1986; 29:2 81 88.

5. Department of Census and Statistics, Ministry of Finance and Planning, Ethnic Affairs and National Integration, Ministry of Health Highways and Social Services 1995; Sri Lanka Demographic and Health Survey $130-42$.

6. World Health Organization Indicators for Assessing Breast Feeding Practices Report of an Informal meeting. World Health Organization Geneva 1991

7. Department of Census and Statistics in collaboration with Ministry of Health, Nutrition and Welfare 2002; Sri Lanka Demographic and Health Survey 184-195.

8. Sorenson E, Fernando DN, Hettiarachchi I et al . Exclusive breast feeding practices among women working in the plantations in Sri Lanka. Journal of Tropical Pediatrics. 1998; 44 : 66-68.

9. Department of Labour. Maternity Benefits outcome; Legislative Enactment Revised Edition V.7. 1980.

10. Kisitin N, Benton D, Rao S et al Breast feeding rates among black urban low income women: effect of prenatal education. Pediatrics $1990 ; 86$ (5) 741-46.

11. Jamieson L. Getting it together. Nursing Times 1994; 90 (17) 68 - 69.

12. Perez - Escamilla R, Maulen-Randovan I,Dewey KG. The association between caesarian delivery and breast feeding outcomes among Mexican women American Journal of Public Health. 1996; 86(1).89-97. 